\title{
10-Year Experience: Routine Assessment of Health Related Quality of Life in Head \& Neck Cancer Patients
}

\author{
Teresa Sequeira ${ }^{1,2}$, Eurico Monteiro ${ }^{1,3}$, Lurdes Carvalho ${ }^{3}$, Augusta Silveira ${ }^{1,2}$ \\ ${ }^{1}$ Faculty of Health Sciences, Fernando Pessoa University, Portugal \\ ${ }^{2}$ Center for Studies and Research in Health of Coimbra University (CEISUC), Portugal \\ ${ }^{3}$ Portuguese Institute of Oncology-Porto, Otorhinolaryngology Service, Porto, Portugal.
}

Submission: December 12, 2017; Published: December 18, 2017

*Corresponding author: Teresa Sequeira, Fernando Pessoa University, Faculty of Health Sciences, Rua Carlos da Maia, 296, 4200-150 Porto, Portugal, Tel: +351 22 5074630; Fax: +351 22 5074637; Email: teresas@ufp.edu.pt

\begin{abstract}
Clinical outcomes are daily used in head and neck oncology clinical practice. Clinical outcome assessments can be classified into categories according to who makes the report: clinician-reported outcome assessment (health professional); observer-reported outcome assessment (caregiver) and patient-reported outcome assessment (patient or proxies). We present our opinion and we share our experience concerning routine assessment of Health Related Quality of Life outcomes and its incorporation in head and neck cancer clinical practice. The critical factors for successful implementation we identified in a decade of experience were: the institutional approval and support, the inclusion of all first line caregivers, the standardization of team objectives and institutional proposes; team formation and training, promotion of defined workflow in daily clinical practice and the continuous monitoring and analysis. Ten years after, our team developed a much broader and inclusive understanding of Health Related Quality of Life importance in the course of the disease. Head and neck cancer patients consider the questionnaires administration as part of the clinical approach - they know that someone, somewhere, will use these patient-centered outcomes to improve healthcare quality - this is also our main goal.
\end{abstract}

Keywords: Head and Neck cancer; Oncology; Quality of life; Patient outcome results; Routine assessment; Implementation; Experience

\section{Introduction}

As researchers in head and neck cancer clinical outcomes for ten years, our major challenges have been: the clear standardization and objective definitions of key outcomes useful for research and clinical practice, the choice of the most appropriate measurement tools validated for the population of interest, providing a plan for potential bias minimization, sensitivity analysis definition and identify critical success factors for routine assessment implementation. We present our opinion and we share our experience concerning the implementation of Health Related Quality of Life (HRQoL) outcomes in routine head and neck cancer clinical practice.

\section{Head and neck cancer: Clinical Outcomes}

Clinical outcomes are daily used in head and neck oncology clinical practice. Clinical outcome assessments can be classified into categories according to who makes the report: clinicianreported outcome assessment (health professional); observerreported outcome assessment (caregiver) and patient-reported outcome assessment (patient or proxies) [1]. Whenever these clinical outcomes can be tested and recorded, usually by healthcare provider, they are denominated objective measures. They are generally called "the black and white outcomes", and they are not subject to a large degree of individual interpretation. They include: mortality and morbidity, survival, recurrence rates, laboratory tests results, objective tumor response, measures of disease activity, remission of disease, toxicity evaluations, functional capacity assessment, family and social support $[2,3]$.

The patient-reported outcomes (PROs) are multidimensional subjective measures. PROs reflect patients' perceptions about their health-status, symptoms, functioning, satisfaction degree with health care, health behaviors and health related quality of life (HRQoL) [1,4-6]. They are well standardized and can be objectively quantified. However, multiple PROs cannot be reduced to a single interpretable number. HRQoL is a multidimensional and subjective concept considered a major issue in the assessment of PROs in oncologic patients. HRQoL has been used both as a concept and as a health outcome measure, related to research and clinical practice $[7,8]$. Frequently, researchers, health professionals and policymakers make too much distinction between subjective and objective measures indeed both are important, non-exclusive but complementary tools that ensure the highest quality of healthcare in head and neck cancer. 
Health Related Quality of Life in head and neck cancer: Why?

HRQoL evaluation is a goal in medicine, leading to a wider comprehension of the impact of both the burden of the disease and treatment options, leading to the development of new strategies and proposals for health promotion [9]. HRQoL assessment facilitates detection of physical, emotional, social and psychological problems and can serve to identify patient risk groups. A better patient-physician communication and the detection of unmet needs are the most frequently reported advantages [10]. Additionally and when related to demographic and clinical data, it can track the course of disease and treatment over time, providing a prognostic marker for survival that supplements traditional clinical factors. Furthermore, the used methodology also enables a focus on effectiveness (survival and quality-adjusted survival) and cost-effectiveness - which are fundamental when considering an economic decision model [11-13].

\section{Health Related Quality of Life in head and neck cancer: How?}

HRQoL was first addressed in a retrospective way since individual data was collected on paper and processed later, at group level. However, for both health care professionals and researchers, the big challenge was to incorporate HRQoL measurements in routine clinical practice in order to improve personalized oncologic care $[11,14]$. HRQoL studies have been conducted with such expectations and important steps are being taken worldwide forwards such ambitious goal. Information technologies have been developed and, an individual approach is now possible- the PROs may be processed in real-time and converted into information with considered clinical utility. Few experiences of HRQoL assessment implementation in routine clinical practice have been successfully reported $[15,16]$. The IPOP developed the Platform for QoL Assessment in Oncology that enables data collection, statistical analysis (Rasch model) in realtime, and translation to a graphic form (unfavorable scores are graphically highlighted). The generated printout also includes results from previous assessments in order to better understand the patient evolution.

Few experiences of HRQoL assessment implementation in routine clinical practice have been successfully reported [1719]. Besides technology, we found that healthcare professional's involvement was crucial. Institutional support, team objectives standardization and first caregiver's inclusion were real facilitators of the whole process. HRQoL monitors training (physicians and nurses) were accomplished through interactive training courses (HRQoL concepts, Platform functioning and result interpretation). HRQOL monitors involved in routine HRQoL assessment implementation, expressed the highest agreement for its relevance in oncology clinical practice; its viability; its usefulness as a health education tool and, above all, as a promoter of patient - centered healthcare. Main initial concerns were related to confidentiality and result interpretation. The continuous monitoring of the implementation process and the discussion - among HRQoL monitors and researchersconsidering all possibilities for solving the identified problems, allowed the reduction of these barriers.

\section{Conclusion}

Implementation and measurements incorporation into routine clinical practice are feasible and practicable. This project was among the firsts to implement the complete procedure of routine HRQoL implementation in clinical practice. The development of a computer platform revealed to be imperative in the process. It allowed data collection by auto-reply, database construction, statistical analysis and its graphic translation. It was shown that the attitudes of healthcare team were positive and the barriers encountered towards successful implementation may be subsequently resolved. The critical factors for successful implementation identified in a decade of experience were:

i) institutional approval and support,

ii) inclusion of all first line caregivers,

iii) standardization of team objectives and institutional purposes,

iv) Team formation and training,

v) definition of a clear workflow in daily clinical practice and

vi) Continuous monitoring and data analysis.

We found that PROs scores are useful, relevant, promote a better patient-physician communication and do not affect the consultation time. We conclude the implementation success of HRQoL assessment in head and neck cancer daily practice depends on institutional leaders' approval and support, interdisciplinary teams and caregivers' involvement. The communication between researchers and health professionals' team minimized the implementation risks and may also contribute to the elimination of all the concerns that inevitably might appear. Ten years after, our team developed a much broader and inclusive understanding of HRQoL importance in the course of the disease and our databases are growing continuously (and therefore, a more robust Rasch analysis). Head and neck cancer patients consider the questionnaires administration as part of the clinical approach - they know that someone, somewhere, will use these patient-centered outcomes to improve healthcare quality - this is also our main goal.

\section{References}

1. Velentgas P, Dreyer NA, Nourjah P, Smith SR, Torchia MM (2013) Developing a Protocol for Observational Comparative Effectiveness Research: A User's Guide. AHRQ Publication No 12(13)-EHC099. Rockville, MD: Agency for Healthcare Research and Quality.

2. Kataria T, Gupta D, Goyal S, Bisht SS, Basu T, et al. (2016) Clinical outcomes of adaptive radiotherapy in head and neck cancers. Br J Radiol 89(1062): 20160085. 
3. Oliver A, Greenberg CC (2009) Measuring Outcomes in Oncology Treatment: The Importance of Patient-Centered Outcomes. Surg Clin North Am 89(1): 17.

4. Bell ML (2017) Challenges to interpreting patient reported outcomes in clinical trials: author rejoinder. Ann Transl Med 5(21):439.

5. Sequeira T, Ferreira PL, Teixeira J, Peres I, Oliveira J, et al. (2015) Patient-Reported Outcomes in Prostate Cancer: Prospective Changes Analysis for Prognosis Prediction. Journal of Cancer Therapy 6(15): 1238-1248.

6. Silveira A, Gonçalves J, Sequeira T, Ribeiro C, Lopes C, et al. (2011) Computer-based quality-of-life monitoring in head and neck cancer patients: a validation model using the EORTC-QLQ C30 and EORTCH\&N35 Portuguese PC-software version. Acta Med Por 24(S2): 347 354.

7. Silveira A, Gonçalves J, Sequeira T, Ribeiro C, Lopes C, et al. (2012). Head and Neck Cancer: Health Related Quality of Life Assessment considering clinical and epidemiological perspectives. Rev Bras Epidemiol 15(1): 38-48.

8. Sayed SI, Elmiyeh B, Rhys-Evans P, Syrigos KN, Nutting CM, et al. (2009) Quality of life and outcomes research in head and neck cancer: a review of the state of the discipline and likely future directions. Cancer Treat Rev 35(5):397-402

9. Romero M, Vivas-Consuelo D, Alvis-Guzman N (2013) Is Health Related Quality of Life (HRQoL) a valid indicator for health systems evaluation? Springerplus 2(1): 664

10. Ernstmann N, Weissbach L, Herden J, Winter N, Ansmann L (2017) Patient-physician communication and health-related quality of life of patients with localised prostate cancer undergoing radical prostatectomy-a longitudinal multilevel analysis. BJU Int 119(3): 396405

11. Giesinger J, Kemmler G, Meraner V, Gamper EM, Oberguggenberger A, et al. (2009) Towards the Implementation of Quality of Life Monitoring in Daily Clinical Routine: Methodological Issues and Clinical Implication. Breast Care (Basel) 4(3): 148-154.
12. Silveira A, Gonçalves J, Sequeira T, Ribeiro C, Lopes C, et al. (2011) Geriatric Oncology: comparing health related quality of life in head and neck cancer. Head Neck Oncol 13: 3-3

13. Jensen SB, Pedersen AM, Vissink A, Andersen E, Brown CG, et al (2010) Salivary Gland Hypofunction/Xerostomia Section, Oral Care Study Group, Multinational Association of Supportive Care in Cancer (MASCC)/International Society of Oral Oncology (ISOO) - A systematic review of salivary gland hypofunction and xerostomia induced by cancer therapies: prevalence, severity and impact on quality of life. Support Care Cancer 18(8): 1039-1060.

14. Velikova G, Booth L, Smith AB, Brown PM, Lynch P, et al. (2004) Measuring quality of life in routine oncology practice improves communication and patient well-being: a randomized controlled trial. J Clin 22(4): 714-724

15. Erharter A, Giesinger J, Kemmler G, Schauer-Maurer G, Stockhammer G, et al. (2010) Implementation of Computer-Based Quality-of-Life Monitoring in Brain Tumor Outpatients in Routine Clinical Practice. J Pain Symptom Manage 39(2): 219-229.

16. Rogausch A, Sigle J, Seibert A, Thüring S, Kochen MM, et al. (2009) Feasibility and acceptance of electronic quality of life assessment in general practice: an implementation study. Health Qual Life Outcomes 3: $7-51$

17. Velikova G, Keding A, Harley C, Cocks K, Booth L, et al. (2010) Patients report improvements in continuity of care when quality of life assessments are used routinely in oncology practice: Secondary outcomes of a randomised controlled trial. Eur J Cancer 46(13): 23812388.

18. Gutteling J, Busschbach J, de Man RA, Darlington AS (2008) Logistic feasibility of health related quality of life measurement in clinical practice: results of a prospective study in a large population of chronic liver patients. Health Qual Life Outcomes 10: 6-97.

19. Hilarius DL, Kloeg PH, Gundy CM, Aaronson NK (2008) Use of healthrelated quality-of-life assessments in daily clinical oncology nursing practice: a community hospital-based intervention study. Cancer 113(3): 628-637.

\section{Your next submission with Juniper Publishers will reach you the below assets}

- Quality Editorial service

- Swift Peer Review

- Reprints availability

- E-prints Service

- Manuscript Podcast for convenient understanding

- Global attainment for your research

- Manuscript accessibility in different formats

( Pdf, E-pub, Full Text, Audio)

- Unceasing customer service

Track the below URL for one-step submission https://juniperpublishers.com/online-submission.php 